\title{
KONSEP RUANG UME KBUBU DESA KAENBAUN KABUPATEN TIMOR TENGAH UTARA
}

\author{
Thomas Kurniawan Dima, Antariksa, Agung Murti Nugroho \\ Program Magister Arsitektur Lingkungan Binaan, PMDFT, Universitas Brawijaya \\ thomaskurniawan88@gmail.com
}

\begin{abstract}
ABSTRAK
Desa Kaenbaun merupakan desa yang ditempati oleh beberapa suku yang dibagi menjadi dua kelompok yaitu suku laki-laki dan suku perempuan. Desa Kaenbaun memiliki rumah tradisional yang disebut ume kbubu. Ume kbubu menjadi sebuah bangunan yang sangat penting bagi masyarakat Desa Kaenbaun. Tujuan dari studi ini adalah untuk mengetahui konsep ruang sebagai salah satu kearifan lokal di Desa Kaenbaun. Metode yang digunakan adalah metode deskriptif analitis. Analisis dilakukan terhadap ruang pada ke-empat jenis ume kbubu bertiang tunggal. Hasil studi menunjukan bahwa konsep ruang ume kbubu dibentuk oleh aktifitas yang ada pada ume kbubu. Pada ke-empat jenis ume kbubu ini terdapat beberapak konsep ruang yang selalu tetap yaitu area memasak yang berada di bagian belakang ruangan, area istirahat yang berada di bagian kiri atau kanan ruangan, area ritual adat di bagian tengah ruangan, area ruang transisi di bagian depan dan area ruang luar.
\end{abstract}

Kata kunci: Ume Kbubu, Desa Kaenbaun, Konsep Ruang

\begin{abstract}
Kaenbaun village is a village that is inhabited by some of the tribes are divided into two groups, male and female. The traditional house of this village, ume kbubu, plays an important role for the people of Kaenbaun. The objective of this study was to investigatethe concept of space as one of the local wisdom in kaenbaun village, using descriptive analitycal method. This research analysed spaces in four type of single-columned ume kbubu. The result showed the concept space in ume kbubu formed by existing activities. In all four types of ume kbubu, there are some concepts of space remaining constant such as cooking area which is always located on the back of the room, the rest area on the left or right side of the room, area of traditional rituals placed in the middle, transitional area in the front porch, and outdoor spaces area.
\end{abstract}

Keywords: Ume Kbubu, Kaenbaun Village, Concept of space

\section{PENDAHULUAN}

Desa Kaenbaun merupakan desa multi suku yang ditinggali oleh delapan suku yang hidup bersama di dalamnya yang dibagi menjadi empat suku besar yang disebut suku laki-laki (lian mone), yakni suku Basan, Timo, Taus dan Foni serta empat suku kecil yang disebut suku perempuan (lian feto), yakni Sait, Salu, Kolo dan Nell. Suku Basan sebagai suku raja, suku Timo sebagai suku pengurus kehidupan bersama, suku Taus sebagai suku pengatur kesejahteraan, dan suku Foni sebagai suku penjaga keamanan sedangkan suku-suku perempuan merupakan suku pendatang di Desa Kaenbaun (Purbadi,2010).

Ume kbubu merupakan rumah tradisional masyarakat di pulau Timor bagian barat (bagian negara Indonesia) dan termasuk Desa Kaenbaun di dalamnya. Ume Kbubu merupakan bangunan berbentuk bulat dengan atap dengan material alang-alang yang hampir menyentuh tanah. Ume Kbubu berasal dari kata Ume yang artinya rumah dan $K b u b u$ yang artinya bulat sehingga Ume Kbubu artinya rumah yang berbentuk bulat (Timo, 2005). Ume Kbubu dalam kehidupan sehari-hari digunakan sebagai tempat 
tinggal dan melakukan aktifitas seperti memasak, tidur dan lain sebagainya. Sebuah keluarga harus memiliki terlebih dahulu ume kbubu barulah boleh membangun jenis rumah yang lain (Saunoah et. $A l, 2006$ ). Hal ini juga senada dengan yang diungkapkan oleh Purbadi (2010), bahwa ume kbubu di Desa Kaenbaun merupakan the first place dimana ume kbubu menjadi tempat tinggal pertama bagi sebuah keluarga sebelum membangun bangunan yang lain.

Ume kbubu yang ada di Desa Kaenbaun terdiri dari empat jenis yaitu ume kbubu dapur keluarga, ume kbubu anak laki-laki pertama, ume kbubu orang tua, dan ume kbubu induk suku. Dengan adanya ke-empat jenis ume kbubu ini maka memiliki perbedaan ruang juga. Oleh karena itu, perlu untuk mengetahui konsep ruang ume kbubu yang ada ini dengan maksud mempelajari nilai-nilai kearifan lokal dari ume kbubu yang ada di Desa Kaenbaun.

\section{METODE PENELITIAN}

\section{1. $\quad$ Metode Pengumpulan Data}

Pengumpulan data dilakukan dengan cara:

1. Survey lapangan

Survey lapangan dilakukan untuk mengambil data tentang ume kbubu yang ada di Desa Kaenbaun. Ume kbubu yang menjadi sampel dalam amatan adalah ume kbubu bertiang tunggal karena memiliki nilai adat dan sakral bagi masyarakat Desa Kaenbaun. Selain pengamatan, dilakukan juga wawancara langsung kepada pemilik ume kbubu dan juga tua-tua adat yang ada di Desa Kaenbaun.

2. Survey literatur

Survey literatur dilakukan untuk mempelajari teori-teori yang berkaitan dengan karakteristik rumah tradisional khususnya ume kbubu. Selain dari literatur, dilakukan juga browsing lewat internet untuk mempermudah memperoleh datadata yang tidak diperoleh lewat buku-buku yang ada.

\section{2. $\quad$ Metode Analisis}

Data-data yang diperoleh dari hasil pengumpulan data dianalisis secara deskriptif analitis. Analisis karakteristik yang dilakukan terhadap ume kbubu bertiang tunggal meliputi ruang pada ke-empat jenis ume kbubu yang ada di Desa Kaenbaun.

\section{PEMBAHASAN}

Ume kbubu yang ada di Desa Kaenbaun terdiri dari empat jenis yaitu ume kbubu dapur keluarga, ume kbubu anak laki-laki pertama, ume kbubu orang tua dan ume kbubu induk suku. Ume kbubu-ume kbubu ini merupakan rumah yang berbentuk bulat dengan atap berbentuk kerucut. Seluruh material ume kbubu menggunakan material alami yang didapat dari lingkungan sekitar Desa Kaenbaun (Gambar 1).

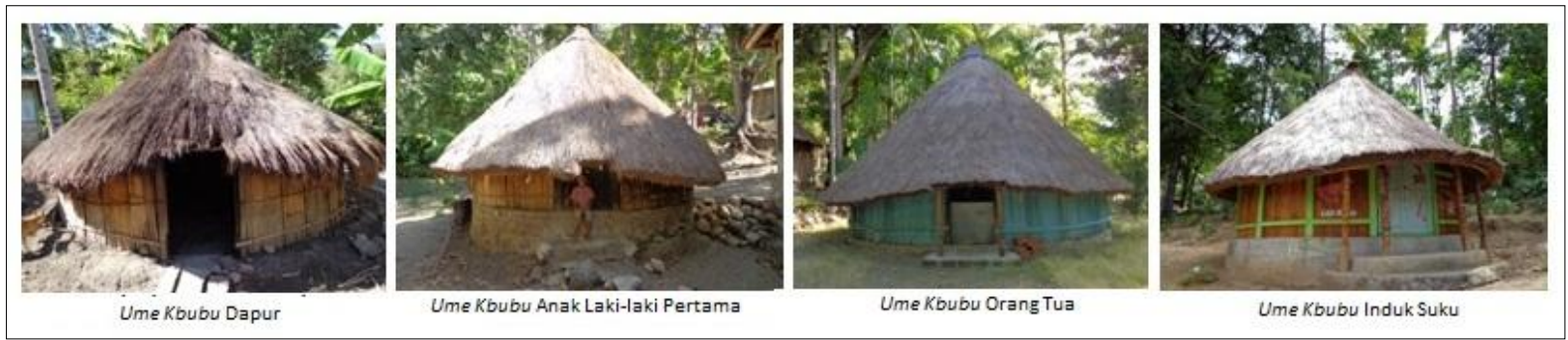

Gambar 1. Jenis Ume kbubu di Desa Kaenbaun 
Nas (2009) menyebutkan rumah tradisional, khususnya yang berada di bagian timur kepulauan Indonesia memiliki karakter yang menjadi tradisi arsitektur dan langgam bangunannya yang biasanya memiliki bangunan dengan lantai melingkar dan berstruktur atap kerucut tinggi seperti bentuk sarang tawon atau struktur atap berbentuk kubah elips. Bentuk ume kbubu sebagai ciri rumah tradisional di Indonesia bagian timur seperti yang diungkapkan tersebut, membuat ruang ume kbubu juga menjadi bulat. Ruang ume kbubu ini ditata masyarakat sesuai dengan tradisi yang telah ada dari zaman nenek moyang. Konsep ruang ume kbubu adalah sebagai berikut:

a. Ume kbubu dapur keluarga

Berdasarkan fungsinya, ume kbubu ini digunakan sebagai dapur keluarga dan juga sebagai tempat tidur keluarga. Ume kbubu ini digunakan juga sebagai tempat untuk mengawetkan jagung. Jagung diletakan diatas tungku sehingga asap hasil kegiatan memasak dapat mengawetkan jagung. Ume kbubu ini tidak memiliki orientasi khusus dan kebanyakan berorientasi kearah rumah modern agar mempermudah akses ketika melakukan aktifitas. Ruang yang terdapat di dalam ume kbubu ini hanya berjumlah satu buah ruang tanpa sekat, tanpa jendela dan hanya memiliki satu buah pintu. Pintu ini menjadi satu-satunya akses untuk masuk kedalam ume kbubu. Walaupun hanya terdapat satu ruang saja dan tidak memiliki sekat, namun keberadaan ruang dalam ume kbubu dapat dirasakan melalui aktifitas yang terjadi didalamnya sehingga membentuk teritori ruang. Teritori yang terjadi dalam ume $k b u b u$ yang digunakan sebagai dapur terbentuk dengan adanya aktifitas memasak yang terjadi di bagian belakang ruang yang terdapat batu tungku untuk memasak, aktifitas beristirahat disamping kiri atau kanan ruang yang terdapat hala (tempat tidur), dan area ritual adat sebagai tempat aktifitas berdoa atau berkomunikasi dengan leluhur ditengah ruangan yang ditandai dengan adanya batu suci yang berada dibawah tiang induk. Teritori pada ume kbubu dapur keluarga ini dapat digambarkan sebagai berikut (Gambar 2 dan Gambar 3):

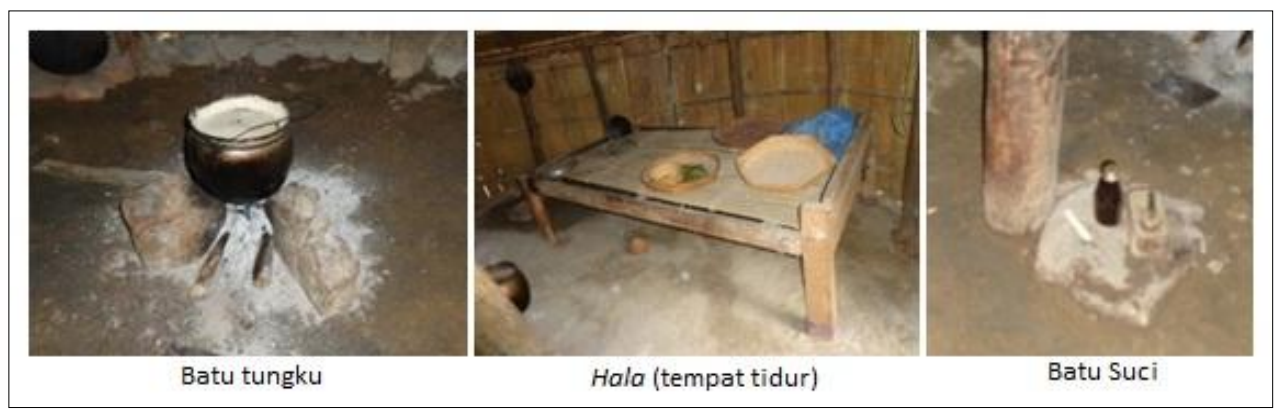

Gambar 2. Elemen-elemen di dalam ume kbubu dapur keluarga

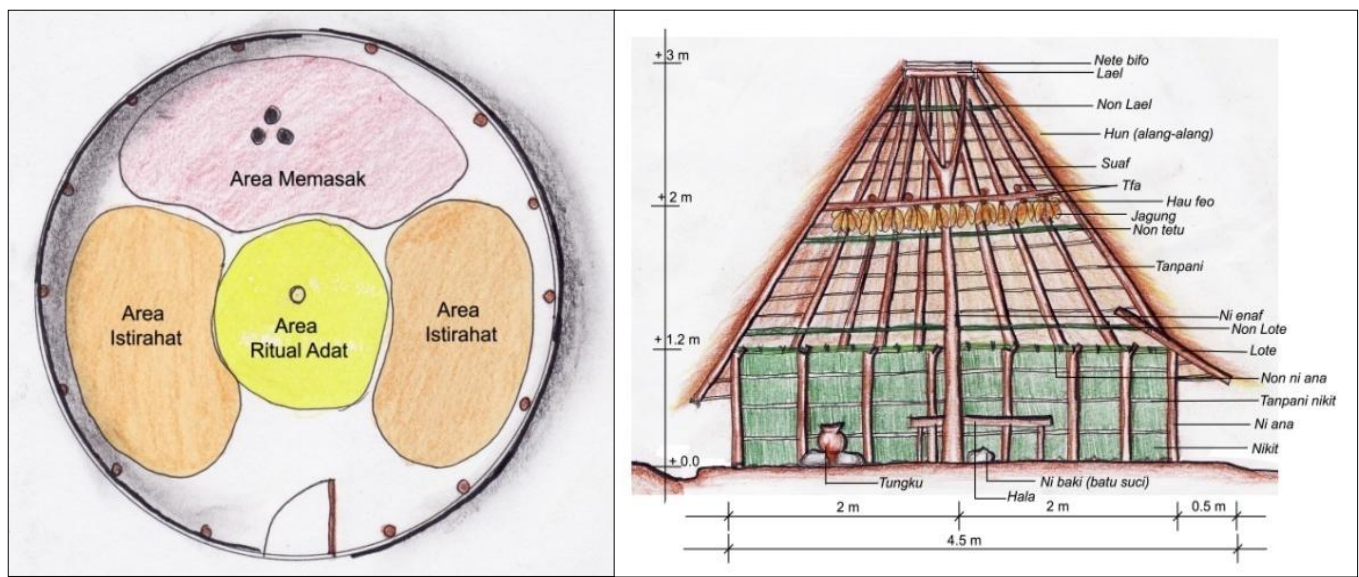

Gambar 3. Konsep ruang dan potongan ume kbubu dapur keluarga 


\section{b. Ume kbubu anak laki-laki pertama}

Ume kbubu ini biasanya digunakan sebagai dapur keluarga dan tempat tidur. Selain kedua fungsi tersebut, ume kbubu ini juga merupakan tempat melakukan upacara adat karena anak laki-laki dianggap sebagai penghubung dengan para leluhur (Purbadi,2010). Ume kbubu ini memiliki memiliki arah orientasi kearah sumber mata air suci yang terlihat pada ume kbubu Suku Taus sedangkan pada ume kbubu suku yang lain ada yang berorientasi kearah gunung dan juga jalan desa. Ume kbubu anak laki-laki pertama hanya memiliki satu buah ruang di dalam ume kbubu dengan ukuran diameter ruangan 5-6 meter. Ruang dalam ini tidak memiliki sekat namun dari aktifitas yang ada dalam ume $k b u b u$, terbentuk teritori ruang yang dapat dirasakan. Teritori ruang yang terbentuk adalah dapur sebagai tempat memasak yang berada dibagian belakang ruangan yang terdapat batu tungku untuk memasak, sebelah kiri dan kanan sebagai tempat beristirahat yang terdapat hala, dan bagian tengah sebagai area sakral tempat berdoa dan berkomunikasi dengan para leluhur yang terdapat batu suci dibawah tiang induk yang disebut ni enaf (tiang perempuan). Selain ruang dalam, terdapat juga ruang luar yang terbentuk karena adanya hau monef dibagian depan ume kbubu. Hau monef ini merupakan altar altar bagi para leluhur yang meninggal secara tidak wajar atau meninggal di luar rumah. Pada saat upacara adat, anggota keluarga duduk melingkari hau monef dan melakukan ritual adat. Konsep ruang ume kbubu anak laki-laki ini dapat dilihat pada gambar berikut (Gambar 4 dan Gambar 5):

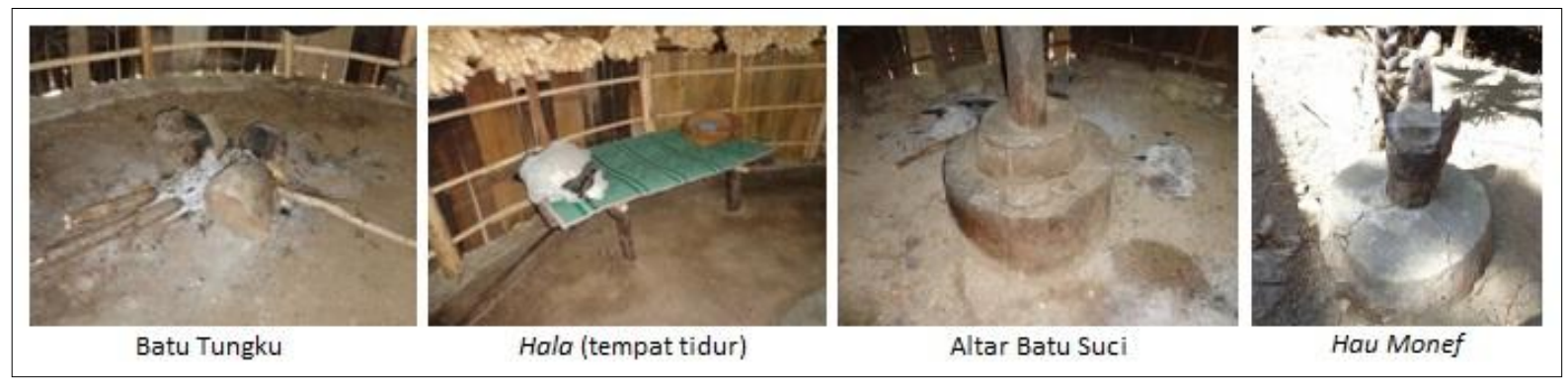

Gambar 4. Elemen-elemen pada ume kbubu anak laki-laki pertama

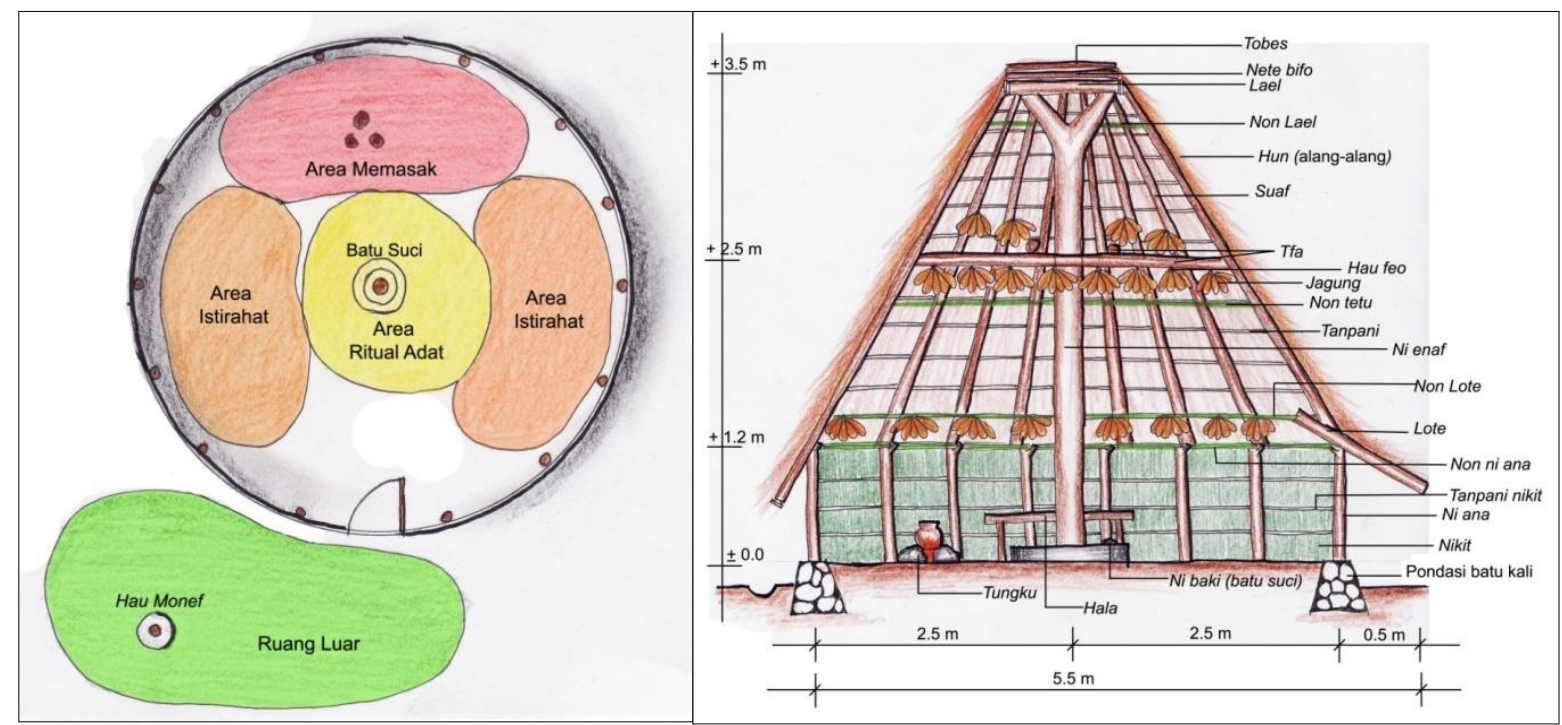

Gambar 5. Konsep ruang dan potongan ume kbubu anak laki-laki pertama

\section{c. Ume kbubu orang tua}

Ume kbubu orang tua merupakan ume kbubu yang dibuat untuk menghormati dan mengenang orang tua. Ume kbubu ini digunakan oleh satu rumpun keluarga suatu suku 
untuk berkumpul dan melakukan upacara adat. Ume kbubu orang tua memiliki orientasi yang berbeda-beda sesuai dengan sukunya misalkan Suku Taus yang berorientasi ke arah sumber mata air suci dan Suku Timo yang beorientasi ke arah daerah asal mereka di daerah Biboki (salah satu kecamatan di Kabupaten Timor Tengah Utara). Ruang pada ume kbubu hanya berjumlah satu ruang dengan ukuran diameter sepanjang 5-6 meter dan tanpa sekat. Walaupun hanya memiliki satu ruangan, namun berdasarkan aktifitas yang ada di dalam ume kbubu maka terdapat beberapa teritori ruang. Teritori ruang yang terbentuk adalah dapur sebagai tempat memasak di bagian belakang ruangan yang ditandai dengan adanya batu tungku untuk memasak dan tempat beristirahat disebelah kiri ruangan ume kbubu yang terdapat hala. Selain kedua area tersebut, terdapat juga area ruang ditengah serta disebelah kanan ruangan sebagai area ritual adat sebagai tempat melakukan upacara adat dan berkomunkasi dengan para leluhur yang ditandai dengan adanya batu suci yang ada di bawah tiang induk. Pada saat upacara adat, semua anggota keluarga duduk melingkari batu suci dan kemudian melakukan ritual adat. Terdapat juga ruang luar yang berada di depan ume kbubu. Ruang ini dibentuk dengan adanya hau monef yang digunakan pada saat upacara adat. Hau monef ini merupakan altar altar bagi para leluhur yang meninggal secara tidak wajar atau meninggal di luar rumah. Pada saat upacara adat tersebut, semua anggota keluarga mengelilingi hau monef dan kemudian melakukan ritual adat. Selain kedua ruang tersebut, terdapat sebuah ruang transisi yang berada di depan ume kbubu berupa teras yang disebut maun nine. Ruang transisi ini digunakan sebagai tempat bersantai sebelum masuk kedalam ume $k b u b u$ ). Konsep ruang ume kbubu orang tua ini dapat dilihat pada gambar berikut (Gambar 6 dan Gambar 7):

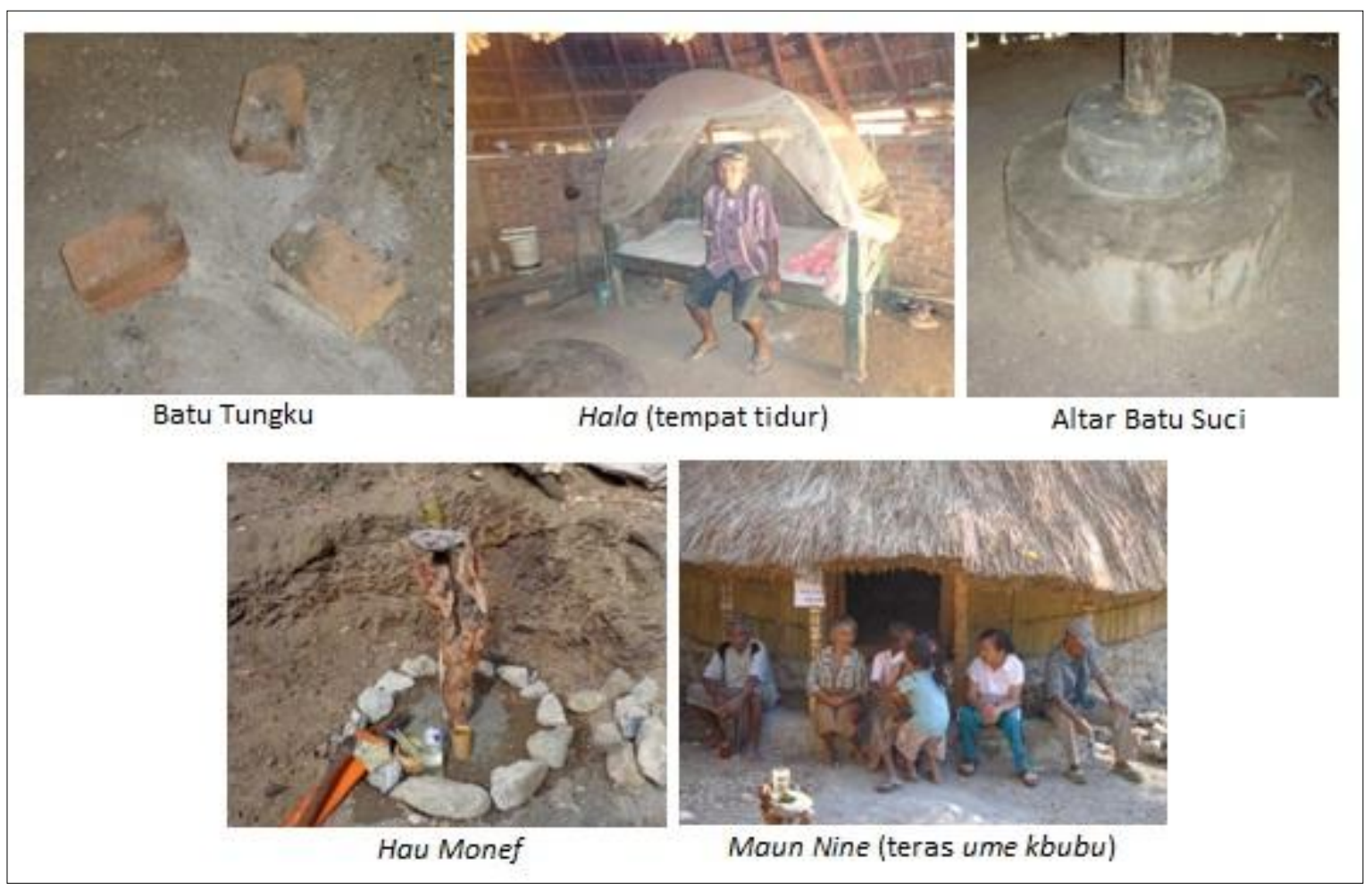

Gambar 6. Elemen-elemen pada ume kbubu orang tua 


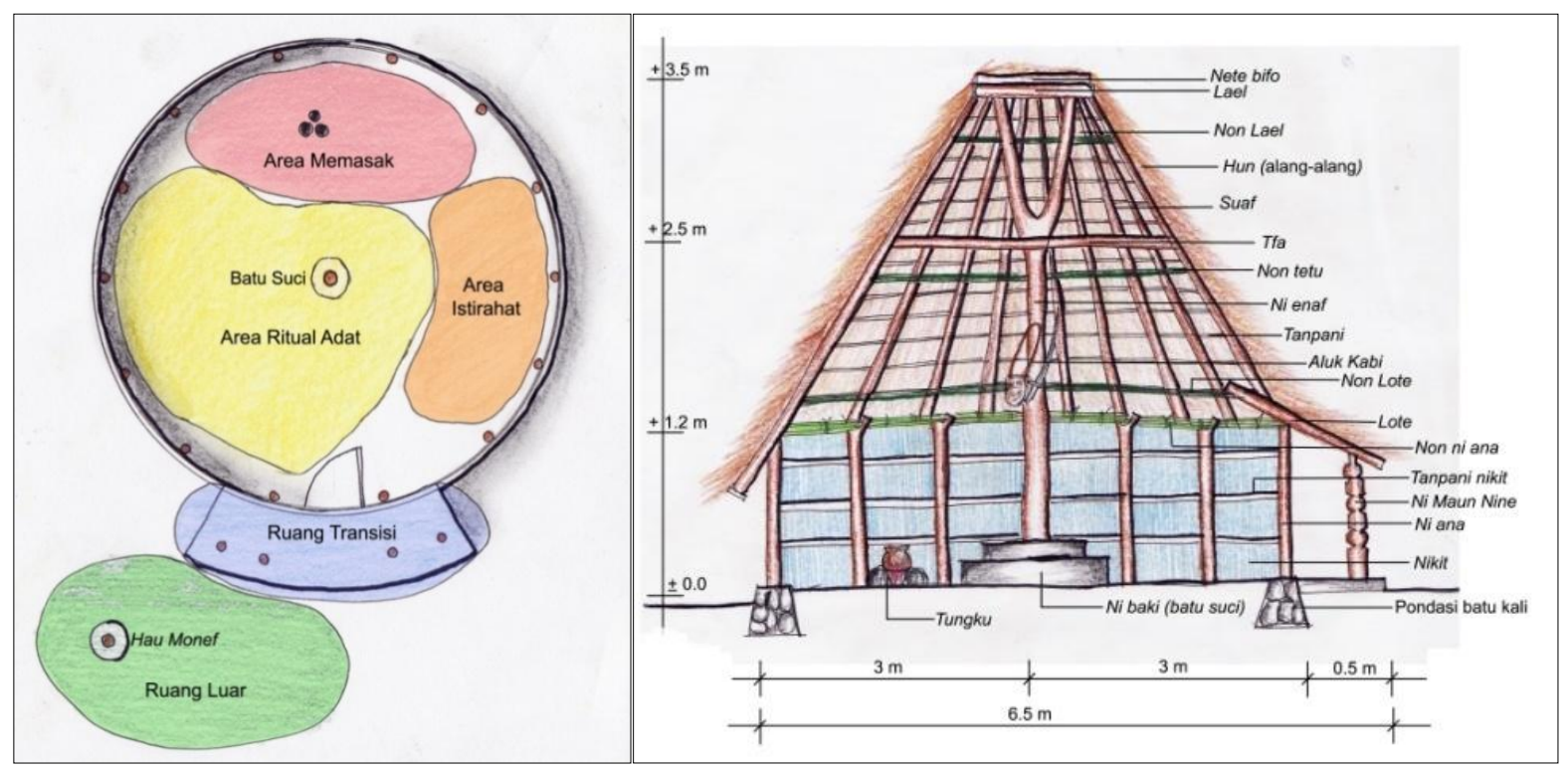

Gambar 7. Konsep ruang dan potongan ume kbubu orang tua

\section{d. Ume kbubu induk suku}

Ume kbubu ini merupakan ume kbubu tempat berkumpul semua anggota setiap suku untuk melakukan upacara adat. Ume kbubu ini memiliki tiga jenis ruang pada ume kbubu suku yaitu ruang dalam, ruang luar dan ruang transisi. Ume kbubu induk suku memiliki orientasi sesuai dengan sukunya masing-masing. Suku Basan berorientasi ke arah gunung batu sebagai tempat awal mula berdirinya Desa Kaenbaun, Suku Timo berorientasi ke arah daerah Biboki yang merupakan daerah asal mereka, Suku Foni mengarah ke darah oekusi (bagian negara Timor Leste) yang merupakan asal mereka, dan Suku Taus mengarah ke neten (puncak gunung) yang terdapat mata air suci. Selain ume kbubu-ume kbubu tersebut sebagai ume kbubu suku laki-laki, terdapat juga ume kbubu Suku Nel sebagai suku perempuan. Menurut kepala Desa Keanbaun yang menjaga ume kbubu ini, tidak ada orientasi khusus namun jika dilihat ume kbubu ini berorientasi ke arah suku-suku laki-laki karena dalam sejarahnya ume kbubu Suku Nel terbentuk dengan ijin dari para tua-tua adat suku laki-laki. Pada ruang dalam ume kbubu suku, hanya terdapat satu ruangan tanpa sekat. Walaupun hanya terdapat satu ruang saja tetapi terdapat teritori ruang yang dapat dirasakan dari aktifitas yang terjadi di dalam ume kbubu. Teritori yang terbentuk dalam ume kbubu adalah area memasak yang terdapat batu tungku berada di bagian belakang ruang ume $k b u b u$, area sakral yang berada di tengah, kiri, kanan dan depan ruangan ume kbubu yang ditandai dengan adanya altar batu suci ditengah ruangan. Pada saat upacara adat, semua anggota suku berkumpul dan mengelilingi batu suci dan kemudian melakukan ritual adat. Terdapat juga ruang luar yang berada di depan ume kbubu yang dibentuk oleh adanya hau monef. Hau monef ini merupakan altar altar bagi para leluhur yang meninggal secara tidak wajar atau meninggal di luar rumah. Pada ruang ini biasanya dilakukan upacara adat dengan mengelilingi hau monef. Selain kedua ruang tersebut, terdapat juga ruang transisi berupa teras yang disebut maun nine. Ume kbubu suku laki-laki, memiliki aturan dimana setiap perempuan yang urusan belis (mas kawin)nya belum selesai tidak boleh masuk ke dalam ume kbubu pada saat upacara adat. Batas bagi kaum perempuan ini hanya boleh sampai pada ruang transisi ini. Khusus bagi suku Basan, pada saat makan pertama hasil panen turis, yang boleh berada di dalam ume kbubu hanyalah kaum laki- 
laki sedangkan kaum perempuan berada di ruang luar di sekitar hau monef. Konsep ruang ume kbubu induk suku ini dapat digambarkan sebagai berikut (Gambar 8 dan Gambar 9):
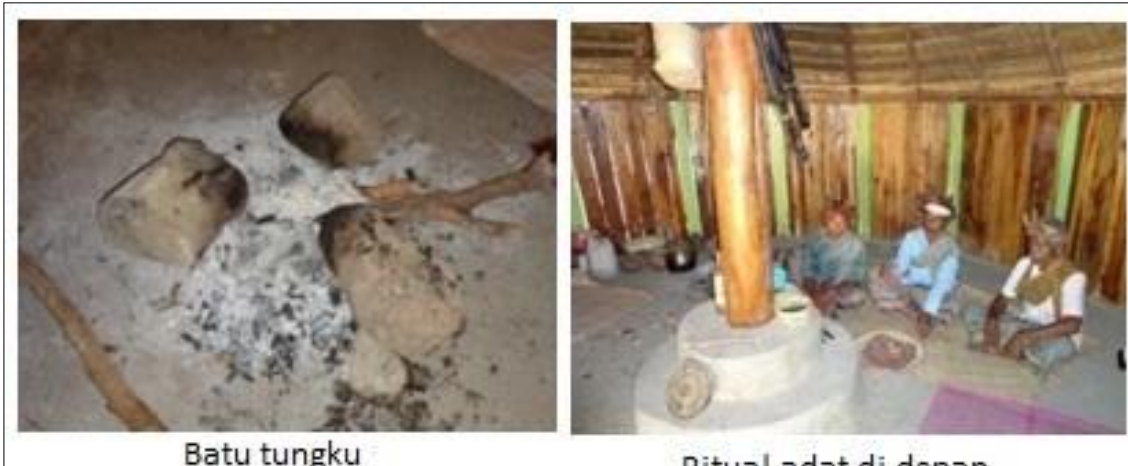

Ritual adat di depan altar batu suci

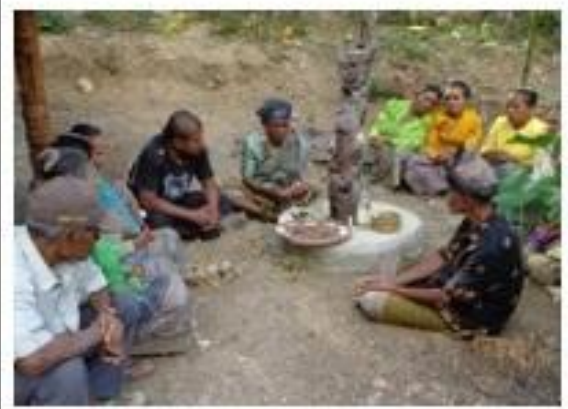

Ritual adat pada hau monef

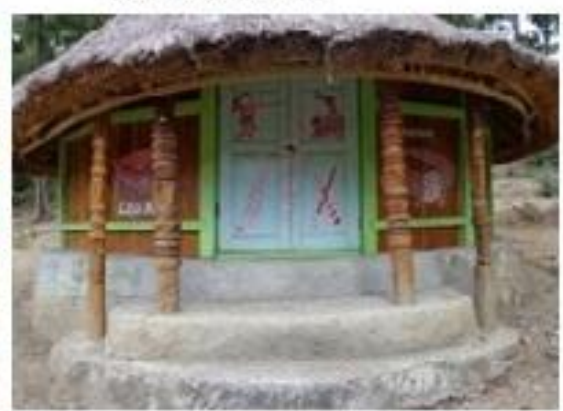

Moun nine (teras ume kbubu)

Gambar 8. Elemen-elemen dan aktifitas pada ume kbubu induk suku
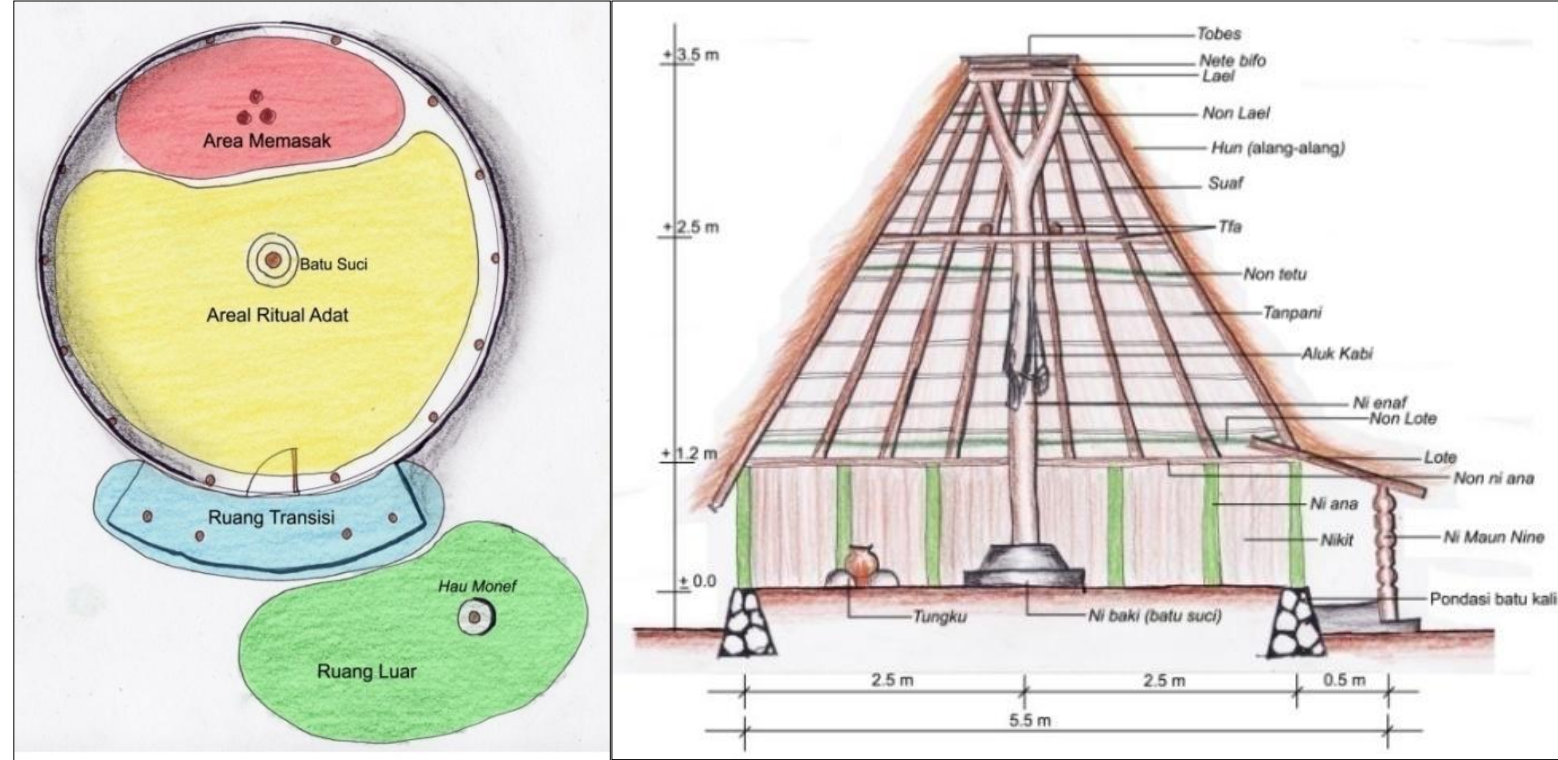

Gambar 9. Konsep ruang dan potongan ume kbubu induk suku

Dari konsep ruang ke-empat jenis ume kbubu ini terdapat beberapa kesamaan teritori dengan posisi yang selalu tetap, yaitu:

a. Area memasak

Area ini berada dibagian belakang ruangan ruangan yang terdapat batu tungku yang disebut tunaf. Tunaf ini merupakan tempat memasak sesajian, memasak makan baru (makan pertama hasil panen) seperti pena'/jagung muda, dan lain-lain dengan air yang diambil oleh penjaga rumah adat dari mata air suku. Menurut 
masyarakat Desa Kaenbaun posisinya selalu berada dibagian belakang ruangan agar tidak membelakangi ni baki (altar batu suci untuk sesajian) dan para arwah tidak boleh dihalangi pandangan mereka untuk turut serta dalam mempersiapkan sesajian. Ini merupakan suatu tanda atau bentuk penghormatan kepada arwah leluhur.

b. Area istirahat

Area ini biasanya terdapat disebelah kiri atau kanan ruangan yang ditandai dengan adanya hala sebagai tempat duduk atau tempat tidur. Pada saat upacara adat seperti upacara pernikahan, hala ini digunakan sebagai tempat duduk bagi pengantin.

c. Area ritual adat

Area ini berada di tengah ruangan yang terdapat batu suci yang digunakan untuk upacara adat. Pada saat upacara adat, semua anggota keluarga setiap suku mengelilingi batu suci kemudian melakukan upacara adat. Batu suci pada ruangan ini selalu berada di bawah tiang ni enaf (tiang induk). Batu suci selalu berada di bawah agar semua orang yang mengikuti upacara adat dapat menundukkan kepala ke tanah sebagai tanda hormat dan juga dapat menyadari bahwa dari hasil tanah manusia dapat hidup. Area ritual adat yang terdapat batu suci selalu berada di tengah ruangan karena bagian tengah ruangan terdapat ni enaf atau ni ainaf yang merupakan pusat kegiatan upacara adat. Posisi ini memiliki makna dalam bahasa Dawan (bahasa masyarakat Atoni Meto) yaitu tnana' yang berarti hati yang murni, tidak bercabang, hanya satu.

d. Ruang transisi

Ruang ini merupakan ruang yang berada didepan ume kbubu sebagai teras ume kbubu yang disebut maun nine. Ruang ini dipakai sebagai tempat duduk sebelum masuk kedalam ume kbubu. Pada ruang ini terdapat empat buah tiang yang disebut ni maun nine yang memiliki ukiran dan menjadi tanda rumah adat. Ruang ini biasanya terdapat pada ume kbubu orang tua dan ume kbubu induk suku.

e. Ruang luar

Area ini selalu berada di depan ume kbubu yang ditandai dengan adanya hau monef. Pada saat upacara adat, semua anggota keluarga setiap suku mengelilingi hau monef dan kemudian melakukan upacara adat. Hau monef selalu berada di depan ume kbubu sebagai simbol bahwa hau monef (tiang laki-laki) sebagai simbol laki-laki melindungi ni enaf (tiang perempuan) sebagai simbol perempuan yang berada di dalam ume kbubu.

f. Orientasi

Setiap rumah tradisional biasanya memiliki orientasi yang menjadi sebuah aturan yang harus dilakukan seperti orientasi rumah jawa yang menghadap ke arah selatan yang merupakan tempat bersemayam Nyi Roro Kidul (Kartono, 2005) dan juga rumah tradisional bali yang memiliki konsep orientsi ruang kaja, kauh, kangin, kelod (Dwijendra, 2003). Ume kbubu yang ada di Desa Kaenbaun juga memiliki arah orientasi yang dapat dilihat pada ume kbubu induk suku yang memiliki orientasi kearah yang menghadap ke sumber atau tempat mereka berasal seperti sumber mata air suci, daerah asal atau gunung batu. Menurut masyarakat Desa Kaenbaun, dengan arah orientasi seperti ini mereka dapat mengingat asal mereka dan juga lebih menghormati leluhur. Selain itu orientasi ini juga bertujuan agar pada saat melakukan upacara adat, para leluhur tidak dihalangi untuk masuk ke dalam ume kbubu. 


\section{KESIMPULAN}

Konsep ruang ume kbubu dibentuk oleh aktifitas yang ada pada ume kbubu. Ruang di dalam ume kbubu hanya berjumlah satu buah tanpa sekat, tanpa jendela dan hanya memiliki satu pintu yang kecil dan rendah. Pada ke-empat jenis ume kbubu ini terdapat beberapa konsep ruang yang selalu tetap yaitu area memasak yang selalu berada dibagian belakang rumah, area istirahat yang berada dibagian samping kiri atau kanan ruangan dan pada bagian tengah merupakan area ritual adat. Pada bagian depan ume kbubu terdapat ruang transisi yang disebut maun nine (teras) yang digunakan sebagai tempat untuk bersantai sebelum masuk kedalam ume kbubu. Maun nine ini biasanya hanya terdapat pada ume kbubu orang tua dan ume kbubu induk suku. Pada bagian depan ume kbubu terdapat ruang luar yang ditandai dengan adanya hau monef sebagai altar bagi para leluhur yang meninggal secara tidak wajar atau yang meniggal di luar rumah. Hau monef ini biasanya hanya terdapat pada ume kbubu anak laki-laki pertama, ume kbubu orang tua dan ume kbubu induk suku. Selain konsep teritori ruang pada ume kbubu tersebut, ume kbubu juga memiliki arah orientasi ke arah asal setiap suku atau ke arah sumber mata air suci dengan maksud agar lebih menghormati leluhur.

\section{DAFTAR PUSTAKA}

Dwijendra, Ngakan Ketut Acwin. 2003. PERUMAHAN DAN PERMUKIMAN TRADISIONAL BALI . JURNAL PERMUKIMAN "NATAH” VOL. 1.

Kartono, J Lukito. 2005. Konsep Ruang Tradisional Jawa Dalam Konteks Budaya. Jurnal Dimensi Interior volume 3 no.2 Desember 2005: 124-136

Nas, Peter J.M., Martien de Vietter. 2009. Masa Lalu Dalam Masa Kini. Jakarta. PT. Gramedia Pustaka Utama

Purbadi, Y. D., 2010. Tata Suku dan Tata Spasial pada Arsitektur Permukiman Suku Dawan di Desa Kaenbaun di Pulau Timor, Disertasi. Program Pascasarjana Fakultas Teknik, Universitas Gadjah Mada.

Saunoah, Hendrikus. Tallan, J.M., Subani, Mathias.2006. LOPO REPRESENTASI SISTIM BUDAYA ATOIN METO TTU. Kefamenanu. Dinas Kebudayaan dan Pariwisata Kabupaten Timor Tengah Utara.

Timo, Eben Nuban. 2005. Pemberita Firman Pencinta Budaya. Jakarta. BPK Gunung Mulia. 